RU Анализ жанровой специфики футбольного комментария на материале английского языка

\author{
Занозина В. В.
}

Аннотация. Цель исследования - определить типологические характеристики жанра футбольного комментария, основываясь на его целеполагании. Научная новизна исследования состоит в том, что в нем уточняется понятийное содержание «жанра» в контексте масс-медийного дискурса, а также выявляются типологические характеристики жанра футбольного комментария на основании лингвистического анализа транскриптных текстов футбольных матчей английских команд. В результате исследования футбольный комментарий был отнесен к жанру масс-медийного дискурса с характерными для него лингвистическими особенностями, связанными с целеполагающими установками комментатора, а также проанализирован в контексте способов подачи информации.

\title{
EN Analysing the Genre Specificity of Football Commentary by the Material of the English Language
}

\section{Zanozina V. V.}

\begin{abstract}
The study aims to determine the typological characteristics of the football commentary genre from the perspective of its goal-setting. Scientific novelty of the study lies in the fact that it clarifies the conceptual content of "genre" in the context of mass media discourse, as well as identifies the typological characteristics of the football commentary genre by carrying out a linguistic analysis of transcript texts of football matches played by English teams. As a result of the study, football commentary has been attributed as a genre of mass media discourse with its distinctive linguistic features associated with the goal-setting attitudes of a commentator and also it has been analysed in the context of ways to present information.
\end{abstract}

\section{Введение}

В настоящее время новые условия и предпосылки медиализации общества обуславливают актуальность дискурс-анализа СМИ в связи с возрастанием их роли в общественной жизни. Футбольный комментарий является узкоспециализированной сферой СМИ, которая вызывает огромный интерес из-за высокой популярности футбола в обществе и из-за его влияния на формирование общественного мнения в рамках отдельно взятой страны и международного сообщества в целом. Данная работа связывает интерес к исследованию медиа с лингвистическим анализом текстов футбольных комментариев как разновидности масс-медийного дискурса, чем и обусловливается ее актуальность.

Заявленная цель исследования определила необходимость решения нескольких задач:

1) проанализировать феномен жанра с разных лингвистических точек зрения;

2) выявить и систематизировать типологические характеристики жанра футбольного комментария, реализуемого в контексте масс-медийного дискурса.

Общелингвистический метод и метод анализа дискурса являются основными методами исследования данной работы.

Решение поставленных задач стало возможно благодаря теоретической базе, представленной трудами, которые посвящены исследованию дифференциации стилистических и жанровых характеристик (Блох, 2011), а также работами, которые исследуют массовую коммуникацию (Харрис, 2003) и жанровую стратификацию масс-медийного дискурса (Тырыгина, 2008).

Практическая значимость работы заключается в том, что материалы исследования могут быть использованы в вузах гуманитарного направления при изучении спецкурсов по теории медиа-дискурса. Полученные данные могут также найти применение в процессе учебно-методической деятельности при создании учебных пособий для студентов гуманитарных факультетов. 


\section{Основная часть}

Определение жанрово-стилевой принадлежности текста футбольного комментария представляет особые трудности, связанные с тем, что до настоящего времени не существует четкого и однозначного определения терминов «стиль» и «жанр». Эта сфера лингвистики представляла интерес для многих ученых-лингвистов в прошлом и также заслуживает внимания в настоящем.

Словарь лингвистических терминов французского языковеда Ж. Марузо (2004) дает следующее, достаточно широкое определение стиля: «Качество высказывания, обусловленное отбором конститутивных элементов данного языка, которые употребляются в определенных обстоятельствах: простой стиль, небрежный, изысканный, искусственный, иносказательный, метафорический, абстрактный и т.д.» (с. 298).

М. Я. Блох (2011, с. 5-6) выделяет четыре значения понятия «стиль»: 1) совокупность характеристик текста, определяющих его выразительность; 2) совокупность характеристик любого предмета, определяющих его отличительные черты; 3) совокупность характеристик некоторой деятельности (ср. стиль поведения, стиль руководства, стиль производства и т.д.); 4) совокупность характеристик рода и вида искусства разных отраслей (стиль трагедии, стиль летописи, стиль пейзажа, стиль камерной музыкальной пьесы и т.д.). Мы вслед за М. Я. Блохом придерживаемся определения стиля как совокупности характеристик текста, определяющих его выразительность.

В современное время в английском языке выделяют пять функциональных стилей. К ним относятся: газетный и публицистический стиль, научный стиль, стиль художественной и деловой речи. Каждый из этих стилей выполняет определенные функции, характерные для того или иного стиля, а также реализует индивидуальные цели. Кроме этого, каждый стиль имеет свои языковые особенности, которые помогают отличать стили друг от друга.

В совокупности всех своих особенностей стили связаны с понятием жанра, если жанр понимать как совокупность языковых средств, характерных для определенного типа речетворческой деятельности. Иными словами, ситуации вокруг нас и предметы высказывания, которые мы выражаем посредством вербальных средств, определяют выбор жанра. Многие исследователи полагают, что стиль и жанр - взаимосвязанные понятия, поэтому для каждого жанра в языке существует своя система языковых средств и свой языковой стиль.

Термин «жанр» вошел в лингвистику из литературоведения и распространился как на художественные, так и на нехудожественные тексты. «Необходимость введения этого термина в область лингвистических исследований стала особенно насущной после того, как внимание исследователей переместилось на единицы выше уровня предложения, а именно: предтекстового и текстового» (Тырыгина, 2008, с. 3).

Стоит также соотносить функциональный стиль и жанр, различие между которыми состоит в том, что функциональный стиль определяется сферой употребления, а жанр - сферой деятельности, которая подчиняется сфере употребления. Получается, что жанр можно считать частным случаем функционального стиля (Тырыгина, 2008, с. 31).

М. М. Бахтин (1979, с. 247-254) является автором работ о речевых жанрах и обращает особое внимание на их разнообразие, что предполагает разнообразие видов человеческой деятельности. Также он утверждает, что жанр можно расценивать как минимальную единицу речи, для которой характерны целенаправленность, завершенность, контакт с действительностью и смысловая полноценность. Таким образом, можно предположить, что в некоторой степени жанр можно считать и единицей текстообразования.

Для более глубокого понимания особенностей жанра следует учитывать, что жанр - это совокупность письменных или устных текстов, имеющих ряд схожих стилистических признаков, которые складываются под воздействием социальной и коммуникативной цели воспроизведения текста, а также в рамках существующих вокруг этого текста адресантно-адресатных отношений (Тырыгина, 2010, с. 100).

В данной работе нас интересует жанровая специфика текстов футбольного комментария, которые формируются под воздействием профессиональной деятельности в среде СМИ и включают в себя участников коммуникации в их адресантно-адресатных отношениях и их социокультурные нормы общения. СМИ это совокупность средств, к которым относятся технические, общественные и человеческие ресурсы для распространения информации в массы (Тырыгина, 2010, с. 105). Следовательно, мы можем сделать вывод, что тексты футбольного комментария формируют определенный жанр, а именно жанр футбольного комментария. В свою очередь, этот тип жанра принято характеризовать как жанр масс-медийного дискурса.

В качестве отдельного жанра масс-медийного дискурса футбольный комментарий можно охарактеризовать как спонтанный или неподготовленный тип дискурса, который напрямую зависит от хода игры. Одновременно с этой характеристикой существует определенная традиционная структура комментария, обусловленная ритуальностью самой игры, позволяющая комментатору выстраивать некоторый план игры и быть подготовленным к некоторым аспектам матча, которые определяются заранее (Тертычный, 2000, с. 157).

Анализ материала на основе футбольных матчей позволил определить структуру комментария, который включает в себя: приветствие и объявление матча и места его проведения, объявление команд, участников матча, а также сигнала к началу игры; основную часть матча, во время которой происходит сама игра, и заключение матча, когда комментатор может сделать вывод о прошедшей игре и попрощаться со зрителем.

Приветственная или вступительная часть матча чаще всего является заранее продуманной, поэтому формально выглядит как небольшой дискурсивный монолог комментатора: Here we go then. Today at the Stratford End. The champions against the ex-champions. Manchester United and Chelsea together. United would love to make 
Chelsea pine for Jose Mourinho after these 90 minutes (устный материал матча (Manchester United v Chelsea..., 2007)). / Поехали! Матч сегодня проходит на стадионе Стретфорд Энд. Чемпионы против бывших чемпионов. Вместе встретились «Манчестер Юнайтед» и «Челси». «Юнайтед» очень хочет сделать так, чтобы после этих 90 минут «Челси» сегодня затосковали по Жозе Моуринью. (В примере уточняется время и место матча, а также названия команд участников.) В конце матча комментатор подводит некоторый итог матча и прощается со зрителями. The champions beat the ex-champions. That's it. Sir Alex triumphs over Avram Grant and Manchester United win again. Fifth consecutive win in all competitions. The Avram Grant era in Chelsea starts with a defeat. Sir Alex... So masterminded victory for United. Tevez gave the lead in the first half and then Saha won and scored from the penalty spot into the last minute. That is it today. Goodbye (устный материал матча (Manchester United v Chelsea..., 2007)). / Чемпионы одержали победу над экс-чемпионами. Вот так! Сэр Алекс Фергюсон обыграл Аврама Гранта, и «Манчестер Юнайтед» снова победил. Пятая по счету победа в соревнованиях. Эра Аврама Гранта в «Челси» начинается с поражения. Сэр Алекс... Такая продуманная победа для «Манчестера». Тевес взял работу на себе в первом тайме, а затем Саа забил пенальти на последних минутах. На сегодня всё. До свидания!

Стандартизированное начало и конец матча с монологическим текстом комментатора в пределах между этими отрезками говорит о композиционной структурности жанра футбольного комментария.

В основной части матча футбольный комментатор становится очевидцем происходящего и подробно описывает действия на футбольном поле, нередко добавляя свое мнение и личную эмоциональную оценку, тем самым оказывая воздействие на зрителя. Основная часть комментария - это неподготовленный монолог, который следует проанализировать с точки зрения использования лингвистических средств, помогающих комментатору вербально передать ситуативную обстановку матча зрителю, что, в свою очередь, формирует жанровые особенности футбольного комментария.

Характерной особенностью жанра футбольного комментария является стремление комментатора передать динамику спортивного события. Способом реализации данной характеристики становится употребление глагольных форм. Распространенное явление футбольного комментария - использование неопределенного времени глаголов (Present Simple). Хотя для описания действия, происходящего в данный момент, наиболее характерно использование длительного времени, например, Present Continuous. Terrific safe! Wayne Rooney thought that was in. Cech had to be at his very best. Well played... and Malouda falls in the middle. Shevchenko tries van der Sar. Maybe there's a lot more than it looked from this side of the pitch... United pleasure it's a red card. Mikel. Well, I've said he's a lucky man if he only gets the yellow card... Well, a second little ball and from Ryan Giggs, outside of his left foot when it comes back to him, he's not offside. The outside of his left foot it does this then (устный материал матча (Manchester United v Chelsea..., 2007)). / Великолепная защита! Уэйн Руни думал, что мяч в воротах. Чех должен был сработать лучше всех. Очень хорошая игра... падение Малуда в центре поля. Шевченко пытается что-то сделать с ван дер Саром. Возможно, мы что-то не видим с этой стороны поля. К радости «Манчестера», это красная карточка! Микел. Я говорил, что ему повезет, если будет желтая. Второй мяч от Райана Гиггза с внешней стороны слева. Это не офсайд. Вот так это происходит.

Использование простого настоящего времени придает речи комментатора динамизм и скорость в связи с быстрой сменой разного рода действий, выраженных глагольными формами.

Эллиптические предложения также являются показателем динамизма и языковой экономии, которая связана с желанием комментатора говорить больше и быстрее в заданном диапазоне времени. United attacking of Stratford in this first half. Giggs and Ferreira together. Will it fall for Rooney? Yes, it will. Terry comes across. Rooney on to his right foot. Tries J. Cole... That will find Ronaldo. Here he is. Tevez is waiting in the middle. Corner. Well, this doesn't shoot the net. Further on over his head. Brown... great head up. Back to Giggs. Good ball in. It is in! Manchester and Tevez. His first goal of Manchester United comes right at the end of the first half. Tevez! (устный материал матча (Manchester United v Chelsea..., 2007)). / «Юнайтед» атакует на стадионе Стретфорд в первом тайме. Гиггз и Феррейра вместе. Это достанется Руни? Да, достанется. Здесь Терри. Руни принимает мяч на правую. Отдает Джо Коулу... Дальше Роналду. Он рядом. Тевес ждет в центре. Угловой. Мяч не попал в сетку. Дальше головой. Браун... Отличный удар головой. Назад Гиггзу. Мяч в воротах. Он в воротах! «Манчестер» и Тевес. Его первый гол за «Манчестер Юнайтед» в конце первого тайма.

Назывные предложения наилучшим образом передают лаконичность высказывания и помогают комментатору визуализировать происходящее в рамках быстро сменяющегося изображения, что продиктовано высокой скоростью футбольного матча. Terrific safe! Corner. Well, this doesn't shoot the net. Further on over his head. Brown... Unusually... United attacking of Stratford in this first half (устный материал матча (Manchester United v Chelsea..., 2007)). / Великолепная защита! Угловой. Мяч не попал в сетку. Дальще головой. Браун... Необычно... «Юнайтед» атакует на стадионе Стретфорд в первом тайме.

Важным аспектом формирования любого жанра является его целеполагающая установка. Как и любой другой жанр, жанр футбольного комментария реализуется и формируется определенным типом адресанта. В связи с чем языковая личность принимает на себя определенную роль, проявляя в этом разное языковое выражение. То есть в данном случае прагматический фактор отдельно взятого субъекта оказывает влияние на формирование текста того или иного жанра (Барнет, 1985, с. 80-132). С другой стороны, жанровая специфика всегда ориентирована на определенного адресата, что приводит к установке процесса коммуникации между адресантом и адресатом.

Коммуникация - это процесс обмена речевыми сообщениями. В своей работе мы опираемся на теорию регуляции речевого общения, выдвинутую профессором М. Я. Блохом (2008 с. 3-7), который полагает, что 
речь по своей сути диалогична, поскольку она всегда кому-то предназначена: либо реальному слушающему (единичному, коллективному или самому себе), либо виртуальному слушающему - «имиджслушающему». Термин «имиджслушающий» (“imagelistener” - образ слушающего) как нельзя лучше подходит для обозначения реципиента такого коммуникативного акта, как футбольный комментарий. Этот образ слушающего присутствует в сознании говорящего.

Согласно этому положению, «говорящий» как центральный субъект общения посылает сообщение, содержащее информацию, при этом роль «слушающего» не менее важна, так как она во многом является целеполагающей для адресанта. Она определяет не только целевое предназначение информации, но и ее формальное содержание, которое зависит от характера запрашиваемых данных. Любая журналистская деятельность на телевидении, радио или в Интернете, в том числе и речь в форме футбольного комментария, может рассматриваться как конкретное проявление речевого общения между говорящим и слушающим.

В футбольном матче взаимодействие комментатора - адресанта - и зрителей - «имиджслушающих» реализуется с помощью риторических вопросов. Right Giggs. Why didn't he handle it? Why doesn't he handle this? Why doesn't he want to clear with a foot? Well, it's a difficult one then again (устный материал матча (Manchester United v Chelsea..., 2007)). / Итак, Гиггз. Почему он не обработал его? Почему он этого не делает? Почему он не отдает мяч? Это довольно сложно.

Комментатор следит за действием игрока, задает несколько риторических вопросов, перефразируя и усиливая эффект удивления и недопонимания ситуации, неоднократно повторяя вопросительное слово “Why?”, что усиливает эффект воздействия. Не имея возможности получить ответ, комментатор сам отвечает на поставленный вопрос. Этот пример является доказательством не только наличия адресата как жанровой особенности футбольного комментария, но и его эмоционального воздействия на зрителя. Will it fall for Rooney? Yes, it will (устный материал матча (Manchester United v Chelsea..., 2007)). / Это достанется Руни? Да, достанется. Комментатор воспринимает зрителя как собеседника и устанавливает с ним коммуникацию.

Данная коммуникативная деятельность насыщена экспрессивными лексическими и синтаксическими средствами. Эмоциональности речи футбольного комментатора способствуют эпитеты в форме прилагательных Terrific safe! Cech had to be at his very best. Oh, what a poor clearance hitting as far as Roопеу (устный материал матча (Manchester United v Chelsea..., 2007)). / Великолепная защита! Чех должен был сработать лучше всех. Какой слабый вынос на расстояние Руни. Синтаксически эмоциональный эффект достигается использованием большого количества восклицательных предложений, что также влияет на эмоциональную подачу информации, когда сообщения становятся интонационно выделенными. What a chance! That's a great ball from Rooney! Mike Dean. What a big decision! The outside of his left foot it does this then. And Tevez there had a great touch. Well, it's a great ball in and Tevez just gets some footing to the goalkeeper. You could have brought it down. Take that chance! Yeah, it's a lovely ball. Could you have brought this down, Ryan? See in Ashley Cole... dangerous ball in. Right, he couldn't bring it down (устный материал матча (Manchester United v Chelsea..., 2007)). / Какой шанс! Какой хороший удар Руни! Майк Дин. Какое серьезное решение! Внешней стороной левой ноги. Тевес коснулся мяча. Отличный мяч в воротах, а Тевез немного потерял опору. Ты бы справился. Нужно воспользоваться этим шансом! Да! Отличный мяч! Смог бы ты справиться с этим мячом, Райан? Эшли Коул... опасный мяч. Действительно. Он с ним справился.

Функциональное своеобразие жанра футбольного комментария диктует использование восклицательных предложений, направленных на усиление эмоционального воздействия на адресата. Индивидуальный авторский стиль комментатора также определяет степень эмоциональности сообщения информации. Наиболее распространенным вариантом восклицательных предложений является повествовательная структура Whatпредложения, маркированная восклицательным знаком. What a chance! What a big decision! / Kaкой шанс! Какое серьезное решение!

Футбольный матч и трансляция в сопровождении комментатора вызывают сильные эмоции и переживания у зрителей, а также большой интерес, поскольку аудитория ждет от комментатора не только объективного описания происходящего на поле, но и новой актуальной информации и вербализации эмоций, которые позволяют чувствовать общность всех причастных к данному спортивному событию. Р. Харрис (2003) объясняет данный масс-медийный феномен как способ порождения специфических эмоций, которые рождаются во время телевизионного просмотра спортивного события. Во время работы комментатор становится своеобразным собеседником, который вместе со зрителями оказывается свидетелем данного спортивного события и одновременно знает о нет больше, чем остальные, в силу своего профессионализма. Объективное и информативное описание футбольного мероприятия является приоритетной задачей спортивного комментатора и Р. Харрисом трактуется как «экспликация комментатором пресуппозитивных данных» (с. 210-212), которая включает в себя достоверную информацию об игроках, командах, турнире, судьях, турнирной таблице, правилах во время игры, об атмосфере события и т.д. Это позволяет нам говорить о еще одной важной особенности жанра футбольного комментария - его дуалистической форме. С одной стороны, футбольный комментарий позволяет аудитории получить новую информацию, а с другой - провоцирует эмоции благодаря эмоциональности самого спорта как рода деятельности.

В качестве отдельного жанра футбольный комментарий можно охарактеризовать как спонтанный или неподготовленный тип дискурса, который напрямую зависит от хода игры.

Таким образом, главным отличительным свойством футбольного комментария является одновременная информативность и экспрессивность при сообщении информации. 


\section{Заключение}

В рамках данного исследования мы пришли к следующим выводам: жанр следует считать совокупностью устных и письменных текстов, которые имеют ряд схожих стилистических признаков, а футбольный комментарий следует считать жанром масс-медийного дискурса, который имеет неподготовленный и спонтанный характер, что напрямую определяет жанровую специфику этого типа дискурса. Кроме этого, жанр футбольного комментария отличает одновременная информативность и экспрессивность при сообщении информации, структурная композиция и определенные языковые средства разного уровня, которые, во-первых, передают динамизм, событийность и скорость спортивного события, а во-вторых, эмоциональное восприятие матча, реализованное соответствующим образом. Таким образом, в данной работе были выделены типологические характеристики жанра футбольного комментария.

Перспективы дальнейшего исследования заключаются в более подробном описании характеристик дискурса футбольного комментария.

\section{Источники | References}

1. Барнет В. Проблемы изучения жанров устной научной речи // Современная русская устная научная речь: в 3-х т. / под ред. О. А. Лаптевой. Красноярск: Изд-во Краснояр. ун-та, 1985. Т. I.

2. Бахтин М. М. Проблема текста в лингвистике, филологии и других гуманитарных науках // Бахтин М. М. Эстетика словесного творчества. М.: Искусство, 1979.

3. Блох М. Я. Предисловие. Некоторые ключевые понятия теории текста // Блох М. Я., Великая Е. В. Просодия в стилизации текста. М.: Прометей, 2011.

4. Блох М. Я. Фактор слушающего в диалогической и монологической речи // Вестник Нижневартовского государственного университета. Серия «Литературоведение». 2008. № 4.

5. Марузо Ж. Словарь лингвистических терминов. Изд-е 2-е. М.: Едиториал УРСС, 2004.

6. Тертычный А. А. Жанры периодической печати: учеб. пособие. М.: Аспект Пресс, 2000.

7. Тырыгина В. А. Жанровая стратификация масс-медийного дискурса. M.: URSS, 2010.

8. Тырыгина В. А. Проблема жанра в массово-информационном дискурсе: автореф. дисс. ... д. филол. н. М., 2008.

9. Харрис Р. Психология массовых коммуникаций. СПб.: Прайм-Еврознак, 2003.

10. Manchester United v Chelsea - Premier League 2007/2008 [видео]. 2007. URL: https://youtu.be/D6kdajLqEtM

\section{Информация об авторах | Author information}

RU Занозина Влада Вадимовна ${ }^{1}$

${ }^{1}$ Нижегородский государственный лингвистический университет имени Н. А. Добролюбова

EN Zanozina Vlada Vadimovna ${ }^{1}$

${ }^{1}$ Linguistic University of Nizhny Novgorod

${ }^{1}$ vladazanozina@gmail.com

Информация о статье | About this article

Дата поступления рукописи (received): 25.10.2021; опубликовано (published): 28.02.2022.

Ключевые слова (keywords): жанр; функциональный стиль; масс-медийный дискурс; жанр футбольного комментария; жанр СМИ; genre; functional style; mass media discourse; football commentary genre; mass media genre. 